\title{
Hydrothermal growth of titania nanowires for SAW device sensing area
}

\author{
Mohd Rosydi Zakaria ${ }^{1,4}$, Sh.Nadzirah S. Ayub ${ }^{3,4}$, Mohd Hafiz Ismail ${ }^{2}$, Shazlina Johari ${ }^{2}$, and Uda Hashim², \\ ${ }^{1}$ Center of Diploma Studies, Universiti Malaysia Perlis, 02100 Padang Besar, Perlis, Malaysia. \\ ${ }^{2}$ School of Microelectronic Engineering, Universiti Malaysia Perlis (UniMAP),02600 Arau, Perlis, Malaysia \\ ${ }^{3}$ NANO-SciTech Centre, Institute. of Science University Technology (UiTM), 40450 Shah Alam, Selangor, Malaysia \\ ${ }^{4}$ Institute of Nano Electronic Engineering,Universiti Malaysia Perlis (UniMAP)01000 Kangar, Perlis Malaysia.
}

\begin{abstract}
Synthesis of titania or titanium dioxide $\left(\mathrm{TiO}_{2}\right)$ is attracted to energy and environmental applications. Here, the growth of nanostructure $\mathrm{TiO}_{2}$ nanowires on $\mathrm{Si}(100)$ substrates by using the two-step method. Different seed layers of $\mathrm{TiO}_{2}$ were deposited by spin coating and annealing, followed by the growth of $\mathrm{TiO}_{2}$ nanowires by using the hydrothermal method. The sol-gel technique was used in preparing the $\mathrm{TiO}_{2}$ solution for the thin film deposition purpose. Acetic acid, hydrochloric acid and tris (2-aminoethyl) amine were used as a stabilizer to synthesize three different $\mathrm{TiO}_{2}$ seed layers. The aim of this study was to understand the role of polycrystalline size on thin film towards the diameter of nanowires grown as a sensing area in Surface Acoustic Wave (SAW) Biosensor. The morphology and structure of the thin film and $\mathrm{TiO}_{2}$ nanowires were characterized using X-Ray diffraction (XRD), scanning electron microscope (SEM), field emission scanning electron microscope (FESEM) and atomic force microscopy (AFM).
\end{abstract}

\section{Introduction}

Surface Acoustic Wave devices have become very important in sensor application such as communication, chemical gas sensing and has been used for many years $[1,2,3]$. Nowadays, these sensors have been applied and used for biological sensor (biosensor) application to detect the DNA and protein $[3,4]$. This project is important because current biosensor have limitation in the term of low sensitivity and low accuracy in biomolecular detection [5]. For this reason these types of sensor were chosen for general biomedical applications due to its advantages in high sensitivity, ease of integration into electronic circuits, and all around robustness [6,7]. SAW Bio-sensors is one alternative offer a great potential for achieving this goal. SAW Biosensing can be achieved by efforts in three significant components called (1) Interface/substrate (2) Transducer (IDT) and (3) Sensing area as shown in Fig.1. The sensitivity of the sensor for surface modifications is increased, by the choice of the sensing area material, and the design of the IDT as well as by the structure of the sensor and the transducers [8]. In SAW biosensor device, sensing area also receives the biggest research interest. It is not only determines the performance quality of the device but also contributes to ultimate detection limit, accuracy and sensitivity [9]. Hence, makes SAW biosensing is highly interdisciplinary in biomolecular selection. Sensing area is typically a biological complex to determine the specificity and contributes to sensitivity. Conventional SAW Biosensor commonly used gold material layer as a sensing area for providing a medium for the transducer to come into contact with the sensing material through strong binding $[9,10]$. However, this technique has several limitations such as may cause contamination problems and put restrictions, e.g. temperature limitation, for the subsequent processes [11]. From the studies, metal oxide materials such as titanium dioxide $\left(\mathrm{TiO}_{2}\right)$ and zinc oxide $(\mathrm{ZnO})$ thin films is another alternative and have been extensively studied for various applications such as solar cells, gas sensors and protective coating [12]. Recently, more researcher focus on the preparation and characterization of nanowire on SAW sensing area, due the sensitivity in the biosensor detection [13].

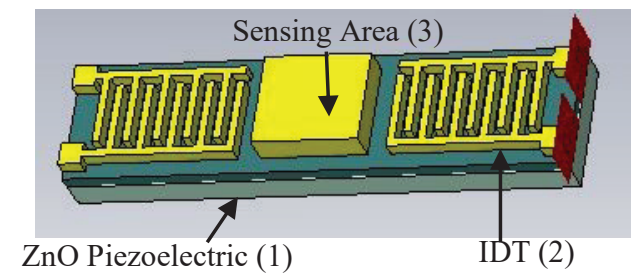

Fig.1. Surface Acoustic Wave (SAW) full structure.

$\mathrm{TiO}_{2}$ or also known as a titanium (IV) oxide or titania is the promising nanostructure metal oxide material have excited tremendous interest due to its various functional properties. $\mathrm{TiO}_{2}$ is an important photoactive material with existing and potential uses in a wide variety of environmental and energy applications, such as photocatalytic oxidation of contaminations [14]. $\mathrm{TiO}_{2}$

\footnotetext{
* Corresponding author: rosydizakaria@unimap.edu.my
} 
also been reported as one of the most suitable semiconductor materials in a wide range of technological applications, such as photo-catalyst, because of its photo-catalytic activity through the irradiation of light at the surface [15]. Nanostructure $\mathrm{TiO}_{2}$ with different morphologies has attracted great on a function of the shape and structure of $\mathrm{TiO}_{2}$ nanomaterials. From the review of this metal oxide material found that that $\mathrm{TiO}_{2}$ are suited for medical application because it is biocompatible and very stable formation [16]. Other than that, the $\mathrm{Ti}$ (Titanium) are chosen because it occurs naturally as an oxide meanwhile $\mathrm{TiO}_{2}$ will used as a main material due to its good biocompability that will allow this material to be as biomolecules detection in biological systems. $\mathrm{TiO}_{2}$ are providing a high chemical stability [17], high resistance to deteriorate in acid or alkali. This material is chosen to form the nanowires due to the advantages which are non-poisonous [18], safe, easy to make and inexpensive $[18,19]$. Due to these advantages the $\mathrm{TiO}_{2}$ nanowire was chosen as a sensing material medium in the fabrication of SAW biosensor devices. To prepare the $\mathrm{TiO}_{2}$ film, many methods can be used such as chemical vapor deposition (CVD), electron beam evaporation, ion sputtering and also the sol-gel method [20,21].

\section{Experimental details}

\subsection{Sampel and substrate preparation}

The (100) Si wafer substrates were cleaned to remove any contamination and particle on the wafer surface. Three cleaning procedures were used which is used Pirahna, RCA and Diluted HF. The piranha is a general cleaning procedure that used to clean organic residues of substrates. After cleaning process, the wafer was going through in the oxidation process. The oxidation process is an adding process, which is adding oxygen to a silicon wafer to form a silicon dioxide on the wafer surface. In this process, dry oxidation was used due to its lower growth rate and better film quality with the thickness of $195 \AA$.

The $\mathrm{ZnO}$ layer then growth on the silicon substrate as a piezoelectric material. The sample then continued with aluminum deposition for IDT formation. After fabrication of IDT was completed, the fabrication process for sensing area were taking part. Fig. 2 shows the samples of the conventional SAW device after IDT formation was completed.

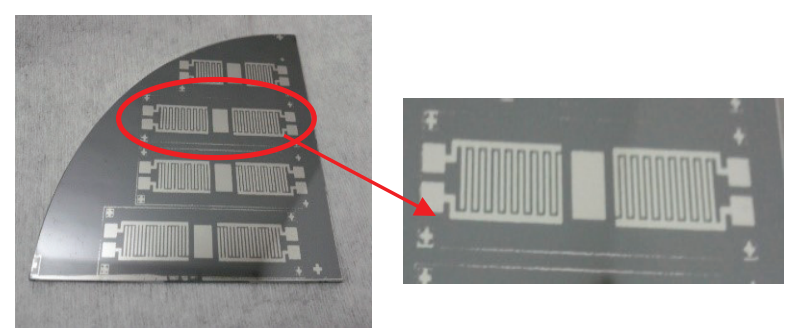

Fig.2. The completed fabrication of conventional SAW device.

\section{2 $\mathrm{TiO}_{2}$ Film Deposition}

In this part, there were two main processes which are $\mathrm{TiO}_{2}$ solution preparation and process for thin film coating. For the solution preparation, it used three different catalysts consist of acetic acid, tris (2aminoelthyl) amine and hydrochloric acid ( $\mathrm{HCl})$. In this project, these three solutions were prepared by using the sol gel technique. Samples were labeled as Sample 1, Sample 2 and Sample 3 for acetic acid, $\mathrm{HCl}$ and tris (2aminoelthyl) amine respectively. For the sample 1, there are three components used to produce $\mathrm{TiO}_{2}$ thin film namely, titanium (IV) isopropoxide TIP $\left(\mathrm{Ti}\left(\mathrm{C}_{3} \mathrm{H}_{7} \mathrm{O}\right)_{4}\right)$ as a titanium precursor, ethanol $\left(\mathrm{C}_{2} \mathrm{H}_{5} \mathrm{OH}\right)$ as a solvent and acetic acid $\left(\mathrm{CH}_{3} \mathrm{COOH}\right)$ as a stabilizer with a fixed ratio of 1:9:0.1. Acetic acid were used to stabilize the solution and to slow down the hydrolysis process [22]. Acetic acid stabilizer was replaced by $\mathrm{HCl}$ and tris (2aminoelthyl) amine for Sample 2 and 3 respectively. .

After the solution had been prepared, the next step was the coating process where the solutions was doped onto the $\mathrm{SiO}_{2}$ substrates. A layer of $\mathrm{TiO}_{2}$ film was spin coated on the substrates by using a spinner with certain parameters. Then, the sample was going through for annealing process certain time and temperature before being cool at room temperature. Finally, this $\mathrm{TiO}_{2}$ thin film is characterized by using SEM for thickness and XRD for phase structure. Table 1 summarizes the process steps for all solution preparation of $\mathrm{TiO}_{2}$ film.

Table 1. Process step for preparing $\mathrm{TiO}_{2}$ film coating

\begin{tabular}{|l|c|c|c|}
\hline \multicolumn{1}{|c|}{ Sample } & $\mathbf{1}$ & $\mathbf{2}$ & $\mathbf{3}$ \\
\hline \multicolumn{1}{|c|}{ Precursor } & \multicolumn{2}{|c|}{ Titanium Isopropoxide TIP $\left(\mathrm{Ti}\left(\mathrm{C}_{3} \mathrm{H}_{7} \mathrm{O}\right)_{4}\right)$} \\
\hline $\begin{array}{l}\text { TiO } 2 \text { solution } \\
\text { stabilizer }\end{array}$ & Acetic acid & $\begin{array}{c}\text { Hydrochlori } \\
\text { c acid (HCl) }\end{array}$ & $\begin{array}{c}\text { 2aminoethyl } \\
\text { amine }\end{array}$ \\
\hline Solvent & $\begin{array}{c}\text { Ethanol } \\
\left(\mathrm{C}_{2} \mathrm{H}_{5} \mathrm{OH}\right)\end{array}$ & $\begin{array}{c}\text { Ethanol } \\
\left(\mathrm{C}_{2} \mathrm{H}_{5} \mathrm{OH}\right)\end{array}$ & $\begin{array}{c}\text { Isopropyl } \\
\text { alcohol }\end{array}$ \\
\hline Ratio & $1: 9: 0.1$ & $1: 9: 0.1$ & $1: 9: 0.1$ \\
\hline
\end{tabular}

\section{$2.3 \mathrm{TiO}_{2}$ nanowire growth}

For nanowires growth, titanium butoxide $\left(\mathrm{Ti}\left[\mathrm{O}\left(\mathrm{CH}_{2}\right)_{3} \mathrm{CH}_{3}\right]_{4}\right)$, hydrochloric acid $(\mathrm{HCl})$ and distilled water were mixed together. In a typical of hydrothermal synthesis, Solutions were mixed under magnetic-stirrer in a Teflon-lined stainless steel autoclave for $10 \mathrm{~min}$. Then, $0.51 \mathrm{~mL} \mathrm{Ti}\left[\mathrm{O}\left(\mathrm{CH}_{2}\right)_{3} \mathrm{CH}_{3}\right]_{4}$ was added into the mixture as a small droplet. The solutions then were stirred continuously for another 30 min. In the hydrothermal growth process, the precoated substrates were immerged horizontally with the coated side was kept face down inside the Teflon-liner containing the growth precursors. The autoclaved that contains the substrates was sealed and be annealed in the vacuum oven at $175^{\circ} \mathrm{C}$ for $4 \mathrm{~h}$. After that, the autoclaved was cooled at the room temperature for a few hours. The substrates were finally washed with distilled water to 
remove any residual and followed by air-drying [23]. Steps were repeated for 1 and $3 \mathrm{~h}$ annealing process.

The $\mathrm{TiO}_{2}$ nanowires then had been characterized by using PAN analytical X'Pert Pro X-ray diffractometer with $\mathrm{Cu} \mathrm{K} \alpha$ radiation at $\lambda=1.5406 \AA$. The $\mathrm{X}$-ray diffraction (XRD) pattern was recorded in the range of $20^{\circ}$ to $60^{\circ}$ operating at $45 \mathrm{kV}$ and $20 \mathrm{~mA}$. Morphological studies were performed using field emission scanning electron microscopy (FESEM, HITACHI SU8020) and Atomic Force Microscopy (AFM) SII Sciko Instrument INC SPI3800N Probe station. While the nanowires growth were analysed by Scanning Electron Microscopy (SEM, JEOL,JSM6460LA).

\section{Results and Discussion}

Fig. 3 shows the 3D AFM images of $\mathrm{TiO}_{2}$ thin film of (a) Sample 1, (b) Sample 2 and (c) Sample 3 which were deposited on $\mathrm{SiO}_{2}$ substrate. It is clearly observed that the grain size of the $\mathrm{TiO}_{2}$ thin films deposited on $\mathrm{SiO}_{2}$ substrates increases significantly from Sample 1, 2 and 3. The grains growth have spherical shaped for Sample 1 and 2 while Sample 3 has bigger and elongated grains. Thus the Root Mean Square (RMS) surface roughness were increase from 1.337, 2.09 and $2.29 \mathrm{~nm}$ for Sample 1,2 and 3 respectively. The increment in surface roughness can be related to the increase in crystallite size.

(a)

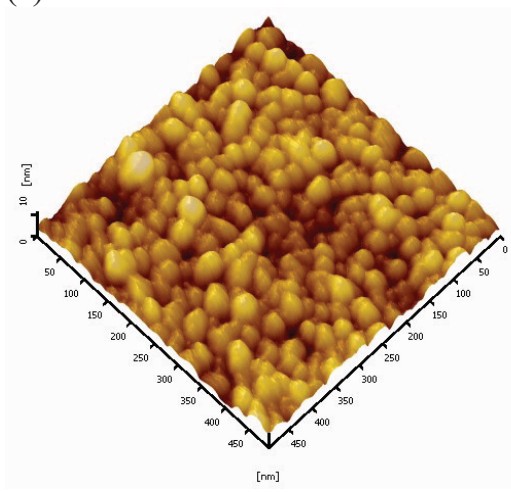

(b)

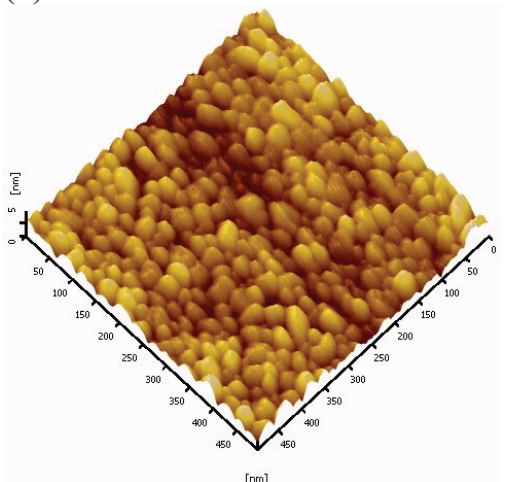

(c)

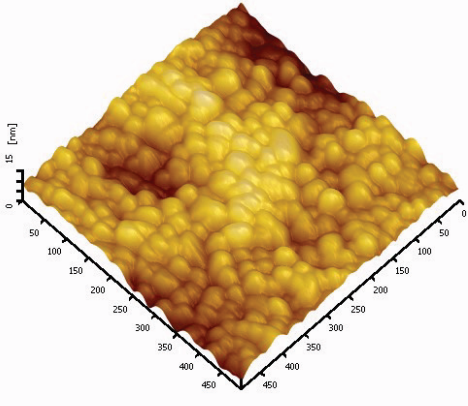

$[\mathrm{mm}]$

Fig. 3. 3D AFM image of $\mathrm{TiO}_{2}$ thin film annealed at $600{ }^{\circ} \mathrm{C}$ for (a) Sample 1, (b) Sample 2 and (c) Sample 3.

Further confirmation of the morphological $\mathrm{TiO}_{2}$ can be seen through FESEM image as shown in Fig. 4. It can be seen that nanoparticles were uniformly growth in the range of 19,31 and $21 \mathrm{~nm}$ at $600{ }^{\circ} \mathrm{C}$ annealing temperature.

(a)

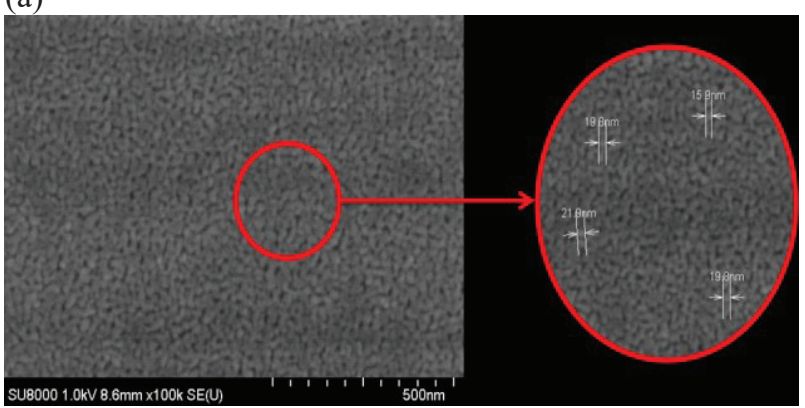

(b)

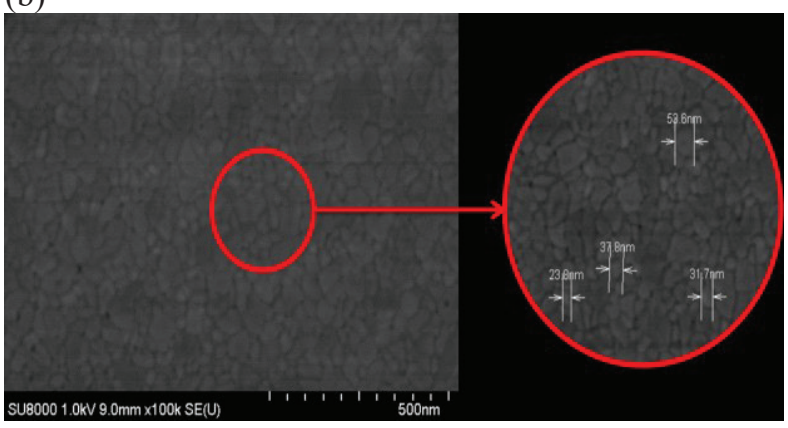

(c)

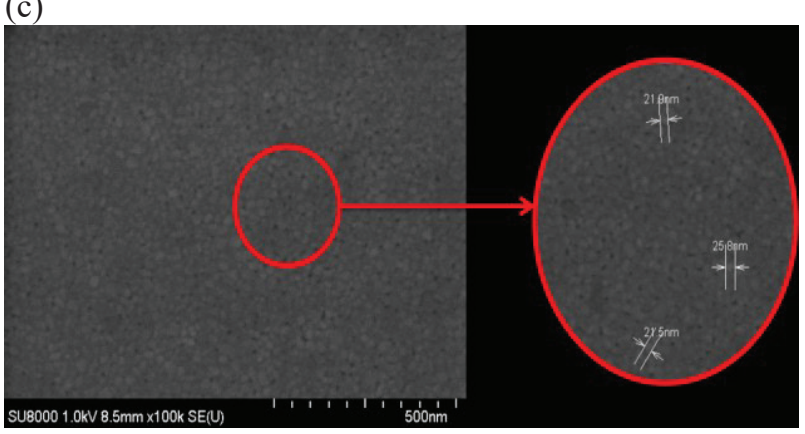

Fig. 4. 2D FESEM image of $\mathrm{TiO}_{2}$ thin film of (a) Sample 1, (b) Sample 2 and (c) Sample 3.

The crystalline structure of the nanoparticles was studied by XRD as shown in Fig. 5. The diffraction peaks were indexed according to JCPDS File No. 21- 
1272 for anatase and JCPDS File No. 21-1276 for rutile. There are anatase (101), (004) and rutile (210) peaks occur when acetic acid was used as stabilizer namely as Sample 1. Only one anatase (101) peak occurs for Sample 2 which used hydrochloric acid as stabilizer and Sample 3 has (101), (111) and (210) rutile peaks. The average crystalline size can be calculated using the Scherer equation.

$$
\mathrm{r}=0.9 \lambda / \mathrm{B} \cos \theta
$$

here $\lambda$ is the $\mathrm{X}$-ray radiation and $\mathrm{B}$ is the full-width at half-maximum of the diffraction peak. The calculated crystallite size values of $\mathrm{TiO}_{2}$ films annealed at $600{ }^{\circ} \mathrm{C}$ were 21.56, 33.23 and $28.67 \mathrm{~nm}$ for Sample 1, Sample 2 and Sample 3 respectively. These values were interrelated with measured nanoparticles trough FESEM images. Different size of nanoparticles from multiple seed layers were expected to synthesis different shape and size of nanowires grow. Further confirmation can be seen through SEM images.
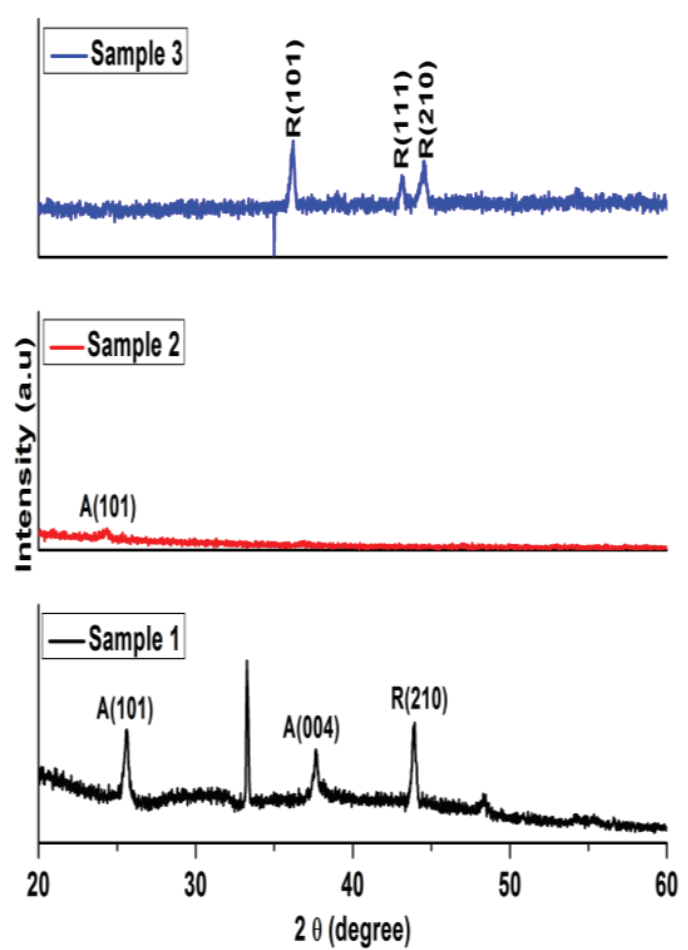

Fig. 5. XRD images of $\mathrm{TiO}_{2}$ thin film for Sample 1, 2 and 3.

Several trends of nanowires growth on different seed layers can be seen in Fig.6-8. There were few nanowires growth on Sample 1 and Sample 3 as seed layers even though only an hour was spent; regarding to the acidic environment of $\mathrm{HCl}$ as stabilizer [23,24]. The length of nanowires was $2.76+/-0.1$ and $4.6+/-0.2 \mu \mathrm{m}$ for Sample 1 and 3 respectively; while no nanowires were observed on Sample 2. When the growth is carried out for longer time (3h), most nanowires appear perpendicular to the $\mathrm{TiO}_{2}$ seed layers with square top. The average diameter and length as determined from
SEM were $0.17+/-0.1$ and $3.76+/-0.2 ; 0.3+/-0.1$ and $5.14+/-0.2$ also $0.23+/-0.1$ and $6.5+/-0.2 \mu \mathrm{m}$ for Sample 1, 2 and 3 respectively.

Finally, after $4 \mathrm{~h}$, the diameter and length of nanowires growth on Sample 2 were $0.36+/-0.1$ and $9.2+/-0.2$ $\mu \mathrm{m}$. It was slightly increased however, the pattern changes from square top to semisphere. While a white uniform film consists of nanowires begin to peel-off on the Sample 1 and 3. The film looks like a white paper which can be easily handled by a tweezer and possible to transfer on other substrate in the form of a film. This observation was almost similar to Liu et.al, who studied the $\mathrm{TiO}_{2}$ nanorods growth [24]. According to them, a competition between crystal growth and dissolution caused the wires tends to peel-off. The uniform wires growth tends to peel-off from substrate [23]. Thus, $3 \mathrm{~h}$ is the most suitable time for $\mathrm{TiO}_{2}$ nanowires to grow.
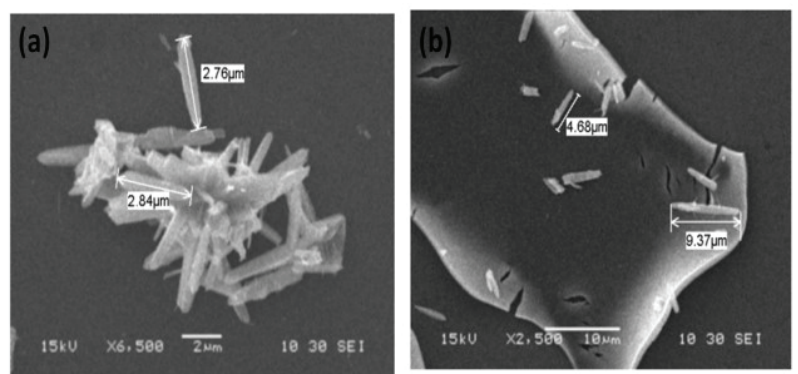

Fig. 6. SEM images of nanowires on (a) Sample 1 and (b) Sample 3 were growth for $1 \mathrm{~h}$.

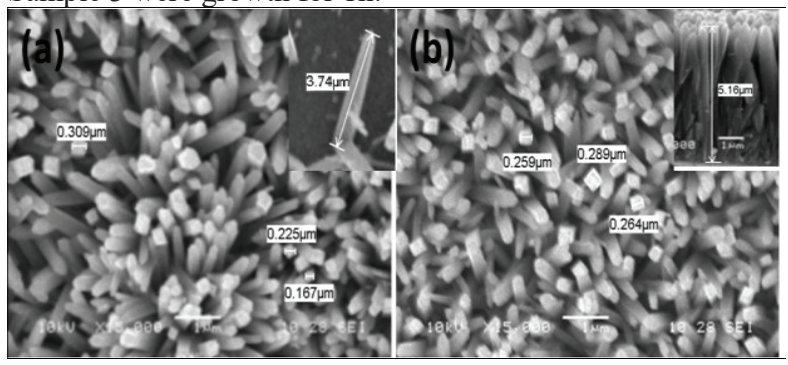

Fig. 7. SEM images of nanowires diameter on (a) Sample 1 and (b) Sample 2, were growth for 3h; the inset is the diameter.



Fig. 8. SEM images of the (a) diameter and (b) length of $4 \mathrm{~h}$ nanowires growth on Sample 2.

Therefore, it is important to get the smallest particle size since it will be affected the diameter of nanowires grown on it. 


\section{Conclusion}

In summary, we have successfully synthesis $\mathrm{TiO}_{2}$ thin film and nanowires with various parameters, including the stabilizer used for thin film preparation using inexpensive sol-gel spin-coating technique, the nanowires growth time applied. From the XRD analysis, high crystalline tetragonal anatase and rutile structures of $\mathrm{TiO}_{2}$ nanoparticles were synthesized in average diameters for acetic acid, $\mathrm{HCl}$ and tris(2-aminoethyl) amine stabilizers were 19, 31 and $21 \mathrm{~nm}$ respectively. From these seed layers, nanowires were growth hydrothermally at different time. SEM image s obviously show that nanowires were only growth at $3 \mathrm{~h}$ with 0.17 $+/-0.1$ and $3.74+/-0.2 ; 0.3+/-0.1$ and $5.14+/-0.2$ also $0.23+/-0.1$ and $6.5+/-0.2 \mu \mathrm{m}$ for Sample 1, 2 and 3 respectively. However, when it further growth to $4 \mathrm{~h}$, the nanowires tend to peel-off.

The authors wish to thank Universiti Malaysia Perlis (UniMAP), for giving the opportunities to do this research in the Micro Fabrication Cleanroom School of Microelectronic Engineering and Institute of Nanoelectronics Engineering (INEE). The appreciation also goes to MOSTI and we are grateful for the funding provided by FRGS 9003:00460

\section{References}

1. David A. Powell, et al., Encyclopedia of Sensors, 5I-M, pp. 245-263 (2006)

2. Lange, K., B. Rapp, and M. Rapp, Surface acoustic wave biosensors: a review, Anal Bioanal Chem., 391: 1509-1519 (2008)

3. Y. Hur, et al., Sensors and Actuators A: Physical. 120(2): p. $462-467$ (2005)

4. Gronewold and T.M. A., Analytica Chimica Acta. 603(2): p. 119-128 (2007)

5. Cular, S., et al, IEEE Sensors Journal, 8(3): p. 314320 (2008)

6. Chou, F.-F. and J.-S. Shih, Sensors and Actuators B: Chemical. 129(1): p. 176-183 (2008)

7. K. Lange, et al., Anal. Chem. 75: p. 5561-5566 (2003)

8. Francis, L.A., J.-M. F, and P. Bertrand, Sensors and Actuators A: Physical. 123-124(0): p. 360-369 (2005)

9. Tigli, O. and M.E. Zaghloul, in Circuits and Systems (MWSCAS) (2010)

10. T.K. Shing, H.H. Pan, I.C. Chen, C.I. Kuo., Tamkang J. Sci. and Eng. 7 (3) p. 135 (2004)

11. S. Venkatachalam, H. Hayashi, T. Ebina and H. Nanjo, Optoelectronics-Advanced Materials and Devices (2013)

12. Watson, S., et al., Journal of Nanoparticle Research. 6(2): p. 193-207 (2004)

13. Peng, W., et al., Sensors and Actuators A: Physical. 184(0): p. 34-40 (2012)

14. Sakulkhaemaruethai, S., et al., Materials Letters. 59(23): p. 2965-2968 (2005)
15. Wu, G., M. Tian, and A. Chen., Journal of Photochemistry and Photobiology A: Chemistry. 233(0): p. 65-71 (2012)

16. Srimala Sreekantan et al, IOP Conf. Ser.: Mater. Sci. Eng. 21012002 (2011)

17. K. Hashimoto, H. IRIE, and A. Fujishima, Japanese Journal of Applied Physics, 44 (No. 12): p. pp. 8269-8285. (2005)

18. U. Diebold, Surface Science Reports,. 48(5-8): p. 53-229. (2003)

19. AN Banerjee., Nanotechnol Sci Appl. 4:35-65. (2011)

20. Sonawane, R.S., S.G. Hegde, and M.K. Dongare, Materials Chemistry and Physics. 77(3): p. 744750. (2003)

21. Ding, Z., et al., Catalysis Today. 68(1-3): p. 173182. (2001)

22. Fan, Q., et al., Journal of Physics D: Applied Physics, p. 2683 (2000)

23. Wu, J., et al., Journal of Materials Research. (2011) 26(13): p. 1646-1652.

24. Liu, B. and E.S. Aydil, Journal of the American Chemical Society. 131(11): p. 3985-3990. (2009) 